\title{
Inclusão digital e desenvolvimento local ${ }^{1}$
}

\author{
Digital inclusion and local development
}

Caroline Queiroz SANTOS²

Ana Maria Pereira CARDOSO ${ }^{3}$

\section{RESUMO}

O artigo procura analisar a inclusão digital como elemento facilitador para o desenvolvimento local. Seu objetivo é analisar e avaliar os ganhos sociais propiciados pelo acesso à tecnologia da Internet por meio de telecentros comunitários, procurando identificar tendências de desenvolvimento local a partir da ampliação do uso das TICs, em uma região caracterizada por pobreza extrema. Descreve-se a experiência do projeto Cidadão NET, iniciativa governamental realizada no Estado de Minas Gerais, que tem a proposta de auxiliar o desenvolvimento humano por meio do acesso às tecnologias e do envolvimento comunitário.

Palavras-chave: inclusão digital; desenvolvimento local; telecentros.

\section{ABSTRACT}

This article aims to analyze and evaluate social gains with the use of information and communication technologies, mainly the internet, in communitarian Telecenters, as a tool for local development. It also tries to identify local development tendencies after the enlargement of TICs practice in a community characterized by extreme poverty The experience of Cidadão.NET Project (Citizen.NET) - a government initiative carried out in Minas Gerais State, Brazil, with the purpose of aiding social development by means of access to information and communication's technologies and communitarian involvement - is described.

Keywords: digital inclusion; local development; telecenters.

\section{INTRODUÇÃO}

Entre os objetivos de desenvolvimento do Milênio, estabelecidos pelas Nações Unidas em 2000, está o de "permitir que as pessoas possam aproveitar dos benefícios das novas tecnologias, especialmente as tecnologias da informação e da comunicação (TICs)", notadamente a internet, um fenômeno que tem causado grande impacto na sociedade, em função das possibilidades de comunicação sem fronteiras que ela

1 A pesquisa que resultou neste artigo foi conduzida no curso de Mestrado em Informática da Pontifícia Universidade Católica de Minas Gerais.

2 Gerente de Projeto. Instituto de Desenvolvimento do Norte e Nordeste de Minas Gerais. Rua Rio de Janeiro, 471 10ªndar, Centro, 30160-040, Belo Horizonte, MG, Brasil. Correspondência para/Correspondece to: S.Q. SANTOS. E-mail: <carol.qs@gmail.com>.

3 Professor Adjunto, Faculdade de Ciência da Informação, Pontifícia Universidade Católica de Minas Gerais. Av. Dom José Gaspar, 500, Prédio 34, sala 212, Coração Eucarístico, 30535-610, Belo Horizonte, MG, Brasil. E-mail: <anacard@pucminas.br>. Recebido em 17/1/2008 e aceito para publicação em 10/9/2008. 
permite. $\bigcirc$ acesso a esse meio de comunicação tem sido visto como alternativa para melhoria da qualidade de vida e bem-estar dos cidadãos, pelo fato de potencializar maior intercâmbio de conhecimentos e experiências entre pessoas, grupos e povos. Isso provocou o surgimento de iniciativas voltadas à promoção do acesso às $\mathrm{TICs}$, o que veio a ser chamado de inclusão digital ${ }^{4}$, objetivando tanto facilitar o acesso às novas tecnologias de informação, ainda muito dispendiosas para grande parte da humanidade, quanto, sobretudo, efetivar a possibilidade de utilizá-las.

A exclusão digital, ou analfabetismo digital, não é um problema apenas do Brasil e vem consumindo investimentos de organizações públicas e privadas, na expectativa de sua superação. Inúmeras têm sido as ações conduzidas em todo o país, visando à promoção da inclusão digital como forma coadjuvante de inclusão social. Nessa direção, adquire relevância o entendimento das repercussões sociais de tais ações, o que constituiu o tema da pesquisa aqui relatada.

O estudo realizado incorporou a concepção de desenvolvimento apontada por Kliksberg (2003, p. 109), para quem

"[...] os objetivos finais do desenvolvimento têm a ver com a ampliação das oportunidades reais dos seres humanos de desenvolver suas potencialidades. Uma sociedade progride efetivamente se os indicadores-chave, como longevidade, qualidade de vida e desenvolvimento de seu potencial, avançam".

Incorporou também o pensamento de Sen (2000), para quem o desenvolvimento local está relacionado não apenas ao fato de a capacidade produtiva de uma comunidade provocar melhoria na qualidade da vida das pessoas, bem como à confiança das pessoas em seu futuro e no da sua comunidade e, sobretudo, à possibilidade de levar adiante iniciativas que contribuam significativamente para a melhoria da vida social. Nesse sentido, a pesquisa buscou verificar se houve alteração significativa de tais indicadores com as ações de inclusão digital empreendidas na localidade estudada. artigo apresenta os resultados de pesquisa empírica realizada em região que está entre as mais pobres do Brasil: o semi-árido de Minas Gerais, com índices socioeconômicos semelhantes aos do nordeste do país. Seu objetivo foi analisar uma experiência de inclusão digital ali efetivada, após três anos de implantação, tendo por base as noções acima citadas. A primeira seção apresenta a contextualização das ações de inclusão digital no Brasil. Em seguida, discutem-se as concepções e propósitos dos telecentros comunitários, modelo que serviu de base para a elaboração do projeto Cidadão. NET, foco da pesquisa. Finalmente, são apresentados os resultados de pesquisa que buscou conhecer os impactos das ações implementadas no desenvolvimento local. $\bigcirc$ intuito do estudo foi o de contribuir para a melhor compreensão das ações de inclusão digital, avaliar suas reais conseqüências para as comunidades beneficiadas, analisar os ganhos sociais e tentar identificar alguma tendência de desenvolvimento local a partir da ampliação do uso das TICs.

\section{INCLUSÃO DIGITAL PARA INCLUSÃO SOCIAL}

De acordo com o "Mapa da Exclusão Digital" (Figura 01) divulgado pela Fundação Getúlio Vargas (FGV), em $2003^{5}$ cerca de 150 milhões de brasileiros ainda não haviam entrado na era digital. Este mapa divulgou o retrato do Brasil em relação ao acesso às tecnologias da informação e da comunicação (TICs) e mostrou, ainda, que também no mundo digital estão refletidas as desigualdades econômicas e sociais do país.

Os dados compilados pelo Mapa da Exclusão Digital indicam que, até aquele ano, apenas 12,46\% da população brasileira tinha acesso ao computador e 8,31\% estavam conectados à internet. Desses, $97 \%$ concentramse em regiões urbanas, deixando as zonas rurais totalmente excluídas. São números reveladores, ainda que se leve em conta a velocidade com que as cifras relacionadas ao acesso e uso da internet se modificam.

\footnotetext{
4 As primeiras propostas de inclusão digital limitavam-se à idéia de oportunizar o acesso a computadores conectados à internet, por meio da criação de telecentros e pontos de presença. Em momento posterior, essa noção foi ampliada, passando a abarcar também a possibilidade de produzir, comunicar e intercâmbiar conteúdos significativos aos atores sociais envolvidos.

5 É fato reconhecido que as estatísticas referentes ao acesso e uso das TICs, notadamente da Internet, são pouco confiáveis em decorrência de seu intenso dinamismo. Por essa razão, optou-se pelo Mapa da Exclusão Digital devido ao amplo reconhecimento social da fonte institucional do estudo.
} 
A possibilidade de acesso à internet foi diagnosticada pela Pesquisa Nacional por Amostra de Domicílios (PNAD), do Instituto Brasileiro de Geografia e Estatística (IBGE) realizada em 2005. Nesse levantamento, constatou-se que, nos 90 dias que antecederam à entrevista, apenas $21 \%$ da população de faixa etária entre 10 e 15 anos havia acessado a internet, pelo menos uma vez, por meio de computador em algum local (domicílio, local de trabalho, escola, centro de acesso gratuito ou outros locais). Já na população compreendida entre 15 a 17 anos de idade, o percentual atingiu $33,9 \%$, maior resultado entre as faixas etárias pesquisadas. Com o aumento da faixa de idade, esse percentual foi diminuindo, atingindo 3,3\% no contingente de 60 anos ou mais de idade. (IBGE, 2005).

Esses índices mudam a cada dia, apresentando tendência ao crescimento, devido à quantidade de ações direcionadas à ampliação do acesso às TICs e, por conseguinte, também à informação que nelas circula. Em 2007, o Instituto Brasileiro de Informação em Ciência e Tecnologia (IBICT), publicou o Mapa de Inclusão Digital, com o objetivo de mensurar o avanço da inclusão digital no país por parte de agentes públicos e privados. No entanto ainda não se sabe, com exatidão, quantos telecentros (ou $\mathrm{PIDs}^{6}$ - Pontos de Inclusão Digital) existem em funcionamento no Brasil.

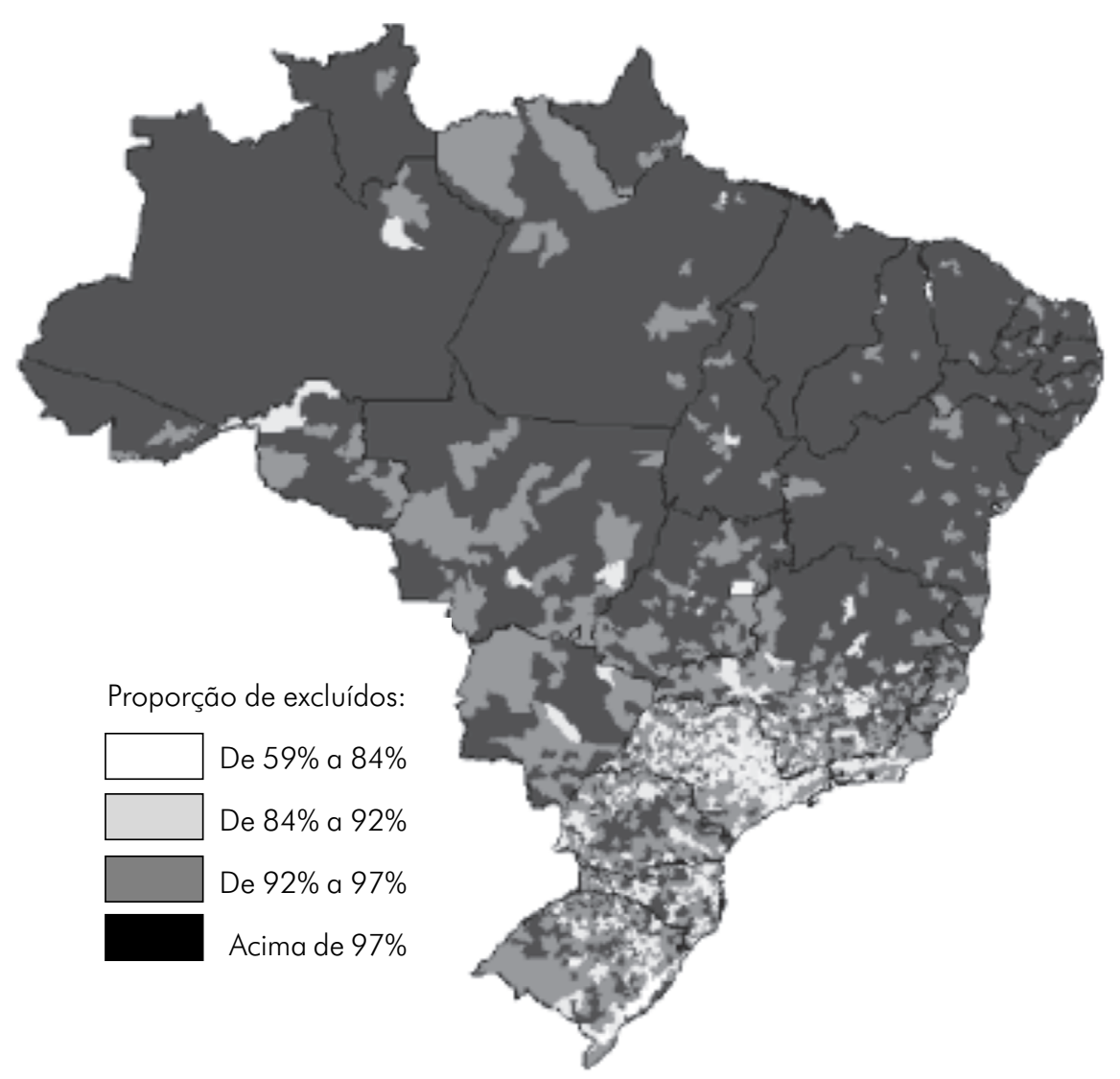

Figura 1. Mapa da exclusão digital.

Fonte: FGV, 2003.

\footnotetext{
6 Pontos de inclusão digital (PIDs): nome utilizado no Mapa de Inclusão Digital para referenciar os locais (telecentros) dotados de um ou mais computadores para acesso público à internet, ou apenas para treinamento em informática.(IBICT, 2007).
} 
De acordo com o IBICT (2007), a pesquisa buscou "levantar informações sobre o acesso público à Internet no Brasil, mediante o tratamento e armazenamento em um banco de dados de iniciativas e projetos de inclusão digital".

Na primeira fase da pesquisa, que deu origem ao mapa publicado no site do IBICT, foram identificadas, em cerca de três mil municípios brasileiros, 108 iniciativas de inclusão digital no âmbito do governo federal, estadual, municipal e terceiro setor. De acordo com o mapa, foram cadastrados 16.722 PIDs.

Há, no entanto, duplicidade em alguns pontos, como por exemplo: o projeto Cidadão.NET (foco da pesquisa aqui relatada) possui, segundo o mapa, 96 PIDs. Esses mesmos PIDs aparecem como pontos ligados ao Programa Governo Eletrônico: Serviço de Atendimento ao Cidadão (GESAC), do Ministério das Comunicações. Ambos são parceiros na iniciativa de inclusão digital, mas isso não é representado no mapa, ou seja, o mesmo PID é contado duas vezes. A figura 02 apresenta a quantidade de PIDs por Estado, segundo o Mapa de Inclusão Digital elaborado pelo IBICT.

Ainda segundo a mesma fonte (IBICT, 2007), para a segunda fase do mapeamento, pretende-se estabelecer um canal direto com cada PID, para que atualizem seus próprios dados e, com isso, seja eliminada a duplicidade de informações da pesquisa, garantindo sua maior consistência e fidelidade.

\begin{tabular}{|c|c|c|c|c|c|c|c|c|}
\hline \multicolumn{9}{|c|}{ Total de PIDs por Estado ('17611 PIDs) } \\
\hline 0 & 500 & 100 & 1500 & 2000 & 2500 & 3000 & 3500 & 4000 \\
\hline SP (3879 PIDs) & عسلس & & 드 & & & I & תו1 & \\
\hline MG (2017 PIDs) & & & $=$ & $\sqsupset$ & & & & \\
\hline PE (1966 PIDs) & & & & & & & & \\
\hline $\operatorname{RJ}(1232 \mathrm{PIDs})=$ & & & & & & & & \\
\hline CE (1050 PIDs) & $=$ & 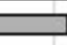 & & & & & & \\
\hline BA (896 PIDs) & 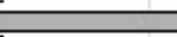 & & & & & & & \\
\hline PR $(831 \mathrm{PIDs})=$ & 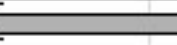 & & & & & & & \\
\hline RS (775 PIDs) & $=$ & & & & & & & \\
\hline GO (584 PIDs) & 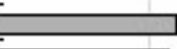 & & & & & & & \\
\hline PA (562 PIDs) & 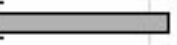 & & & & & & & \\
\hline SC (557 PIDs) & 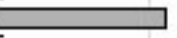 & & & & & & & \\
\hline MA (468 PIDs) & 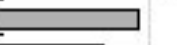 & & & & & & & \\
\hline ES (361 PIDs) $=$ & 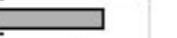 & & & & & & & \\
\hline PB (308 PIDs) & 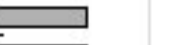 & & & & & & & \\
\hline RN (302 PIDs) $=$ & 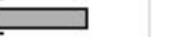 & & & & & & & \\
\hline $\begin{aligned} \mathrm{PI}(270 \mathrm{PIDs}) & = \\
\mathrm{AM}(264 \mathrm{PIDs}) & =\end{aligned}$ & $\square$ & & & & & & & \\
\hline DF (234 PIDs) & 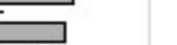 & & & & & & & \\
\hline AL (181 PIDs) & $\square$ & & & & & & & \\
\hline MT (173 PIDs) $=$ & $\square$ & & & & & & & \\
\hline MS (152 PIDs) $=$ & 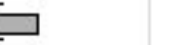 & & & & & & & \\
\hline SE (127 PIDs) & $\exists$ & & & & & & & \\
\hline TO (113 PIDs) & $\sqsupset$ & & & & & & & \\
\hline AP (95 PIDs) & & & & & & & & \\
\hline RO (81 PIDs) & & & & & & & & \\
\hline$\left.{ }_{\mathrm{RR}}^{\mathrm{AC}}(56 \mathrm{PIDS})\right]$ & & & & & & & & \\
\hline
\end{tabular}

Figura 2. Quantidade de PIDs por Estado. Fonte: IBICT, 2007. 
Não é possível estabelecer uma comparação entre os mapas da FGV e do IBICT, uma vez que a unidade de medida não foi a mesma. Mas pode-se perceber um aumento significativo das intenções de se ampliar, ou "democratizar" ", o uso das TICs. Em função disso, estimulou-se uma grande expectativa, em relação às ações de inclusão digital, de que as comunidades "incluídas digitalmente" passarão a ter mais e melhores oportunidades de educação e de geração de renda, com conseqüente influência sobre o desenvolvimento local.

Segundo Câmara (2005), a necessidade de transformar a inclusão digital em política pública tornouse prioritária, visto que o direito de acesso à informação tem sido tratado como questão fundamental ao exercício da cidadania. O ponto de partida para a implementação dessa política pública está no entendimento de que a exclusão digital distancia o cidadão das novas possibilidades e dificulta ainda mais o desenvolvimento social e humano (Câmara, 2005). O processo de desenvolvimento tecnológico acontece de forma extremamente rápida. Isso faz com que aquelas pessoas que não dispõem de acesso a essas tecnologias fiquem cada vez mais afastadas das possibilidades de assimilação do conhecimento pelo seu uso (Silveira, 2003). Segundo Warschaver (2006), no entanto, não é suficiente dar acesso ao hardware: deve-se, também, disponibilizar recursos físicos, digitais, humanos, sociais e relacionais. Dessa forma, deve-se considerar conteúdo, linguagem, alfabetização e educação, comunidade e estrutura institucional, para se permitir o acesso significativo ${ }^{8}$ às tecnologias digitais.

Diversos autores, como Castells (1999), Babe (1995), Albuquerque (2005) e Câmara (2005), acreditam que $\mathrm{o}$ acesso às $\mathrm{TIC}$ e à informação auxilia a promoção do desenvolvimento, uma vez que as pessoas passam a ter ensejo de buscar capacitação profissional, oportunidades de emprego, facilidades de comunicação, paralelamente ao domínio de ferramentas essenciais às atividades de trabalho $e$ educação continuada. Além de possibilitar o surgimento de novas práticas interativas, a tecnologia pode servir para ampliar aquelas já existentes. Ao investigar, num domínio específico, a maneira como as pessoas em geral aprendem, colaboram, partilham e progridem, podem-se buscar as intervenções tecnológicas para ampliar essas práticas.

Segundo Mattos (2006), também no início da "era do rádio" e do advento da imprensa escrita, pessoas já relacionavam o acesso àqueles, então inéditos, meios de comunicação e fontes de informação a processos de ascensão e participação social, o que apenas em parte foi concretizado. No entanto, mesmo minimizando as expectativas, poucos duvidam do fato de que a evolução tecnológica trouxe e continuará trazendo influências sobre os aspectos econômicos, sociais e culturais da nossa civilização.

Nesse sentido, o acesso ao computador e à Internet pode promover um diferencial, uma vez que permite ao cidadão conhecer a realidade de outras comunidades, acompanhar as novidades e acontecimentos no mundo, interagir com pessoas geograficamente distantes, além da liberdade de cada um buscar seu crescimento intelectual por meio de estudos, capacitação profissional e compartilhamento de informações.

Acredita-se que esse acesso significativo às TICs, aliado à compreensão de sua importância pela comunidade, possibilita o desenvolvimento sustentável e a fruição dos seus benefícios. Além disso, a organização comunitária, com o objetivo de montar e manter a estrutura que provê o acesso às TICs, cria um ambiente propício à transformação social. Para Lévy (1999), o fenômeno de interconexão das pessoas pela internet reforça naturalmente a centralidade, o poder dos centros intelectuais, econômicos e políiticos já estabelecidos; mas também é apropriado por movimentos sociais, redes de solidariedade, iniciativas locais de desenvolvimento, projetos pedagógicos, formas mutantes de cooperação e de trocas de conhecimento, que conduzem a experiências de maior participação política, ou seja, em que cada cidadão tem a oportunidade de acompanhar e opinar nas escolhas de sua comunidade. Esse poder, entretanto, nasce da

7 Ao se falar em inclusão digital, tem sido usado o termo "democratização", seja do acesso ou do uso das TICs, no sentido de ampliação da disponibilidade desse acesso ou uso para todas as camadas da população. No presente artigo, a menção a esse termo se faz com as ressalvas decorrentes da compreensão de que não é suficiente o acesso aos meios de comunicação eletrônicos e ao seu conteúdo para ampliar ou fortalecer a participação democrática e cidadã no debate e nas escolhas de interesse público.

8 Por acesso significativo entende-se não só a possibilidade de manejo do computador e suas ferramentas e do acesso à Internet, mas, sobretudo, a capacidade de utilizar estes conhecimentos para o acesso a conteúdos que tenham influência direta para melhoria da qualidade de vida da pessoa, de seu grupo e de sua comunidade. 
capacidade de aprender e de trabalhar de maneira cooperativa, relacionado ao grau de confiança e reconhecimento recíprocos reinantes num contexto social.

\section{INCLUSÃO DIGITAL POR MEIO DOS TELECEN- TROS COMUNITÁRIOS}

Estudar e analisar a inclusão digital significa entender as concepções e abordagens que têm sido construídas paralelamente com a emergência de inúmeros projetos existentes no Brasil e no mundo. Nessa linha, merece destaque o conceito de telecentro comunitário, por sua forte presença na arena da inclusão digital.

Muitas são as definições de telecentro. Para efeito deste artigo, adotaremos a definição de Darelli (2003, p. 26), para quem o telecentro é um

\footnotetext{
"centro de atendimento coletivo que oferece serviços, em regime de parcerias, aos diversos segmentos da sociedade da área urbana e da área rural, utilizando facilidades de telecomunicações e de informática e atuando como agente de desenvolvimento econômico, político e sócio-cultural".
}

Atualmente, muitos projetos de inclusão digital promovem o telecentro comunitário como espaço para disseminação da informação e do conhecimento, além da prestação de serviços. No entanto, segundo Lima (2005), grande parte desses telecentros concentrou seu trabalho na disponibilização do acesso à tecnologia e no treinamento de como utilizar essas ferramentas. $\bigcirc$ acesso, nesses casos, passou a ser fim em si mesmo, e não meio para se alcançarem outros aspectos, tais como conteúdo e educação de melhor qualidade de forma a permitir a mudança social na comunidade. Assim, em um telecentro, se o objetivo é o uso das tecnologias para inclusão social, o foco deve estar nos indivíduos e nos grupos (Warschaver, 2006).

A maioria dos projetos idealiza o telecentro como o estabelecimento onde a política de inclusão digital é colocada em prática. Contudo, como em qualquer outra organização, ali se necessita de regras de trabalho, de estrutura organizacional e de gestão claramente definidas, de modo a estimular a dedicação dos envolvidos e o compromisso com os objetivos do telecentro e sua sustentabilidade. Proenza (2004) afirma que as responsabilidades em um telecentro abrangem contratação e pagamento de pessoal, reformas, manutenção, compras, conectividade, incorporação de trabalho voluntário, supervisão de atividades, prestação de serviços, segurança dos equipamentos, além da assistência e atendimento às necessidades dos usuários.

Também na opinião desse autor, o telecentro, visto como um negócio, não é algo muito complicado, porém está sujeito às mesmas regras implacáveis: se o fluxo de recursos financeiros recebidos não cobrir os custos e não gerar um excedente que permita otimizar a estrutura, cobrir as inevitáveis falhas mecânicas e a obsolescência tecnológica, o empreendimento redundará em fracasso. De acordo com essa visão, os projetos devem buscar atender tais responsabilidades, seja com parcerias locais, com trabalho voluntário, com incentivo do governo, seja com ajuda comunitária, prevendo despesas com estrutura e manutenção e distribuindo tarefas entre os responsáveis pela administração do telecentro.

Para Lévy (1999), isso requer uma ação conjunta dos poderes públicos, de coletividades locais, de associações de cidadãos e de grupos de empresários, visando colocar o ciberespaço a serviço do desenvolvimento de regiões economicamente desfavorecidas, explorando seu potencial de inteligência coletiva: valorização das competências locais, organização das complementaridades entre recursos e projetos, intercâmbio de saberes e de experiências, redes de ajuda mútua, maior participação nas decisões políticas, abertura planetária para diversas formas de especialidades e de parcerias.

Silveira (2001) defende a multiplicação dos telecentros em todas as áreas de exclusão social ${ }^{9}$ como estratégia para a defesa da cidadania ativa, podendo resultar na construção de uma ampla rede pública de comunicação. Quanto maior o número de telecentros, maior a possibilidade de envolvimento direto da

\footnotetext{
9 Por "áreas de exclusão social" ou "comunidades excluídas" entendemos aquelas em que não há efetivação da cidadania. De acordo com Schwartzman e Reis $(2002$, p.6), são regiões nas quais, "apesar da legislação social e do esforço das políticas sociais, uma grande massa de indivíduos não logra pertencer efetivamente a uma comunidade política e social. Indivíduos que vivem no espaço de uma sociedade nacional aportam contribuições a essa sociedade, mas não têm acesso ao consumo dos bens e serviços de cidadania. Embora a lei lhes garanta direitos civis, políticos e sociais, tal garantia legal não se traduz em usufruto efetivo de tais direitos."
} 
população nas questões governamentais e maiores as condições de atuação cidadã. Resta saber se a concretização de tais idéias comprova as expectativas.

\section{A PESQUISA SOBRE INCLUSÃO DIGITAL E DESENVOLVIMENTO}

Em decorrência dos pontos acima apontados, buscou-se identificar uma situação onde fosse possível verificar se existem desdobramentos concretos de ações de inclusão digital para o desenvolvimento local. Optou-se, assim, pelo estudo do projeto Cidadão.NET (a ser tratado adiante), tanto pela facilidade de acesso aos dados e aos atores envolvidos, como por se tratar de projeto recentemente implantado em área de exclusão social e extrema pobreza. Acreditava-se que a circunstância de implantação recente propiciaria aferir eventuais transformações sócio-culturais a partir do acesso às TICs pelos habitantes locais, e analisar a eficácia do Cidadão. NET como política pública de inclusão digital. Para isso, optou-se pela realização de estudo de caso em uma comunidade onde tivesse sido implantado um telecentro e onde, até então, não existia qualquer outro local para acesso às TICs.

Para o desenvolvimento do estudo foi escolhido o método de pesquisa qualitativa, com cunho participante, uma vez que promoveu a interação dos atores do telecentro com a pesquisadora e gestora do projeto, em condições, portanto, de influir nos seus desdobramentos futuros. Envolveu a obtenção de dados predominantemente descritivos, enfatizando mais o processo do que o produto e preocupando-se em retratar a perspectiva dos participantes da situação investigada (Triviños, 1987).

Previamente à pesquisa de campo, realizou-se análise detalhada da documentação oficial do projeto (IDENE, 2003), de forma a contextualizar o cenário e a possibilitar a interpretação dos dados apurados empiricamente.

A pesquisa de campo foi conduzida no Telecentro Comunitário Cidadão.NET localizado no assentamento rural do Projeto Jaíba ${ }^{10}$, norte de Minas Gerais, em funcionamento desde julho de 2004. Instalado na gleba
"F", Núcleo Habitacional 02, onde residem aproximadamente seiscentas famílias, o telecentro foi implantado na expectativa de contribuir para facilitar o dia-a-dia da população, assim como para seu crescimento pessoal e profissional.

A pesquisa de campo foi realizada em três etapas:

a) na primeira, buscou-se conhecer os atores principais do Telecentro: Educador.NET e Comitê Gestor, por meio de entrevistas segundo roteiro pré-definido;

b) na seguinte, o foco foram os usuários do telecentro, por meio da resposta a questionário aplicado aos setenta e quatro usuários que compareceram ao telecentro durante três dias escolhidos aleatoriamente, durante visita da pesquisadora ao local.

c) finalmente, foram entrevistados os oito integrantes do Comitê Gestor que puderam comparecer ao local no dia da visita e as três Educadoras. NET que atuam no telecentro, com a finalidade de aprofundar a percepção inicial.

Concluído o levantamento de dados por meio das entrevistas e da aplicação dos questionários, deuse início à etapa de sua análise, a qual serviu de aporte à construção das afirmações sobre o caso, o que nos levou a identificar, ou rejeitar, eventuais tendências de desenvolvimento social na comunidade do Projeto Jaíba desde a implantação do telecentro, como será relatado a seguir.

\section{PROJETO CIDADÃO.NET}

Dentre as muitas ações para promover a inclusão digital e social de forma efetiva, foi elaborado e vem sendo implantando, desde 2003, o projeto Cidadão.NET, iniciativa do Governo do Estado de Minas Gerais, por meio do Gabinete da Secretária de Estado Extraordinário para o Desenvolvimento dos Vales do Jequitinhonha, Mucuri e Norte de Minas e do Instituto de Desenvolvimento do Norte e Nordeste de Minas Gerais (IDENE) ${ }^{11}$. O Cidadão. NET visa

10 Projeto Jaíba é uma iniciativa de colonização em terras públicas (devolutas) irrigáveis, dedicada à fruticultura, à olericultura e a outras culturas tradicionais.

1 Nesse projeto, o IDENE contou com a parceria do Governo Federal por meio do Ministério de Desenvolvimento Social e Combate à Fome (MDS) e do Ministério das Comunicações, além do apoio de instituições educacionais, de pesquisa e desenvolvimento tecnológico e universidades da região em seu entorno. 
promover o acesso às novas tecnologias da informação e da comunicação para as comunidades localizadas na área de abrangência do IDENE ${ }^{12}$, por meio de um programa sustentável de inclusão digital com a implantação de telecentros comunitários: núcleos de informação e cidadania (IDENE, 2003).

$\bigcirc$ projeto assume como desafio preparar os habitantes da região para o exercício efetivo e amplo da cidadania, utilizando as TICs para acessar, processar, produzir e disseminar conhecimentos que contribuam para a capacitação profissional, para a geração de empreendimentos com vistas à melhoria das condições de trabalho e renda familiar, assim como a implementação de campanhas e ações comunitárias, especialmente nas áreas de educação, saúde e meio ambiente, com foco no desenvolvimento sócioeconômico local.

O projeto Cidadão.NET foi implantado em 03 etapas, sendo a primeira composta de 36 telecentros comunitários em localidades selecionadas conforme os critérios: 1) município-sede de associação microrregional ou de consórcio intermunicipal; e 2) os dois municípios com a maior taxa de analfabetismo dentro de cada associação ou consórcio intermunicipal. Na segunda etapa, 40 municípios foram contemplados, seguindo o critério de mais baixo Índice de Desenvolvimento Humano (IDH), além de priorizar a região do Vale do Mucuri, situada no nordeste de Estado. A terceira etapa contemplou 16 municípios integrantes do Consórcio de Segurança Alimentar (CONSAD), na região do baixo Jequitinhonha.

\section{ASPECTOS TÉCNICOS DO TELECENTRO COMU- NITÁRIO DO CIDADÃO.NET}

com acesso à internet via satélite (Very Small Aperture Terminal (VSAT) ${ }^{13}$ - de 256 kbps, provido por meio da parceria com o GESAC ${ }^{14}$.

A estrutura de rede local do telecentro Cidadão.NET é composta de um servidor de internet, um servidor de dados e seis a oito estações de trabalho sem disco rígido, como mostra a Figura 3. As estações de trabalho têm capacidade de processamento local e realizam a inicialização pela rede, funcionando como terminais inteligentes. A carga de processamento é balanceada entre o servidor e a estação para otimização dos recursos computacionais, agregando economia e flexibilidade ao telecentro.

sistema que possibilita o funcionamento da estrutura de terminais inteligentes no telecentro é o LibertasBR - Etherboot, no qual, segundo Leitão et al. (2004), " [...] pode-se conceber desde ambientes onde todas as aplicações sejam executadas nas estações, até sistemas onde todas as aplicações rodam remotamente no servidor. Ambientes com balanceamento de carga, com algumas aplicações rodando no servidor e outras nas estações, são configurados pela simples instalação de aplicativos em diretórios compartilhados ou não, respectivamente" (p.4).

No Cidadão.NET, optou-se pelo uso de software livre, por considerar que o trabalho com programas abertos pode garantir, além de economia na aquisição de licenças de uso, a liberdade de estudar os códigos e procurar especialização para as áreas técnicas de acordo com os seus interesses. Conforme Guesser (2006) muitos projetos de inclusão digital, além de utilizar software livre, operam sob o paradigma do Movimento de Software Livre (MSL), ou seja, mesmo inseridos em estruturas governamentais clássicas, conseguem impor uma nova relação de interação entre os poderes constituídos e os cidadãos. Assim, esperase que o espírito de colaboração existente nas comunidades de software livre contribua para a efetivação da gestão participativa e colaborativa do telecentro, ao envolver governo e sociedade civil em parceria para as ações de inclusão digital.

\footnotetext{
12 Região norte e central do Estado de Minas Gerais, Vale do Jequitinhonha, Vale do Mucuri e parte do Vale do São Mateus - composta de 188 municípios com os piores indicadores socioeconômicos do Estado.

13 VSAT é uma estação de telecomunicações responsável pela transmissão e recepção de sinais de telecomunicações para o satélite. 14 O GESAC é um programa de inclusão social do Governo Federal, coordenado pelo Ministério das Comunicações, que utiliza as TICs para promover inclusão digital. Além da conectividade, a proposta do programa é oferecer aos usuários uma cesta de serviços em software livre que envolve e-mail, escritório, laboratório virtual, hospedagem de páginas e canal de notícias, com foco no desenvolvimento econômico, cultural e pedagógico das comunidades (GESAC, 2006).
} 
No caso do telecentro do Cidadão.NET, a parceria com o Departamento de Ciência da Computação (DCC) da Universidade Federal de Minas Gerias permitiu o provimento e a manutenção da distribuição Linux ${ }^{15}$ que é utilizada nos telecentros, o LibertasBR. Essa distribuição oferece uma solução para os ambientes de escritório e educacionais, abrangendo desde a edição de textos, planilhas eletrônicas, navegação na internet, até recursos multimídia, como rádio via internet e edição de vídeo (LibertasBR, 2006). Foi desenvolvido, também pelo mesmo parceiro, o
Sistema de Gestão dos Telecentros, que é composto de dois componentes principais: cadastro de usuários e monitoramento de rede. O cadastro é um módulo não apenas de cadastramento dos usuários e membros dos telecentros, como também de organização de cursos e turmas, disponibilizado por meio da WWW. Outro componente importante deste conjunto é o sistema de monitoramento, baseado no software livre Nagios, o qual permite avaliar a utilização de vários recursos, como, por exemplo, os aplicativos que são utilizados pelos usuários finais (LabSL, 2006).

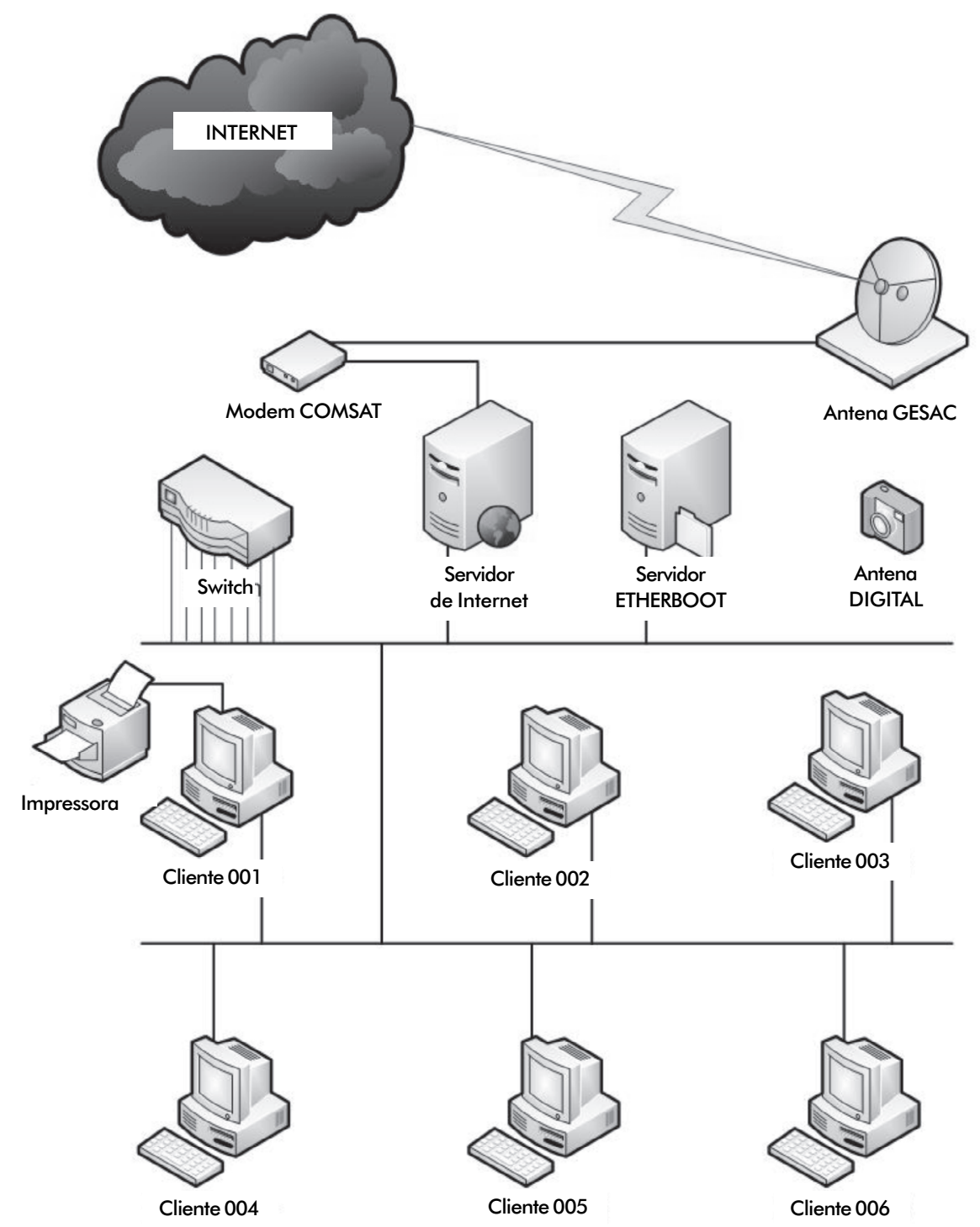

Figura 3. Estrutura da rede local do telecentro. Fonte: GESAC, 2006.

15 Software de código aberto ou livre. 
O suporte técnico aos telecentros é provido por equipe de técnicos do IDENE por meio de chat, e-mail, telefone e visitas periódicas com o objetivo de transferir conhecimento e permitir que a comunidade se aproprie das tecnologias ali disponibilizadas. A comunicação entre os atores do projeto é realizada por meio de listas de discussão, e-mails, aplicativos de mensagens instantâneas, telefone e fax, correspondências via correio e por meio de visitas periódicas aos telecentros pela equipe do projeto e técnicos dos escritórios regionais do IDENE.

\section{PARTICIPAÇÃO COMUNITÁRIA NO CIDA- DÃO.NET}

Na literatura estudada, a participação da comunidade tem sido tratada como um poderoso instrumento para o desenvolvimento. Ao se envolver na implementação de projetos, a comunidade passa a acompanhar a efetivação de políticas públicas, exigindo transparência das ações e a prestação de contas, o que auxilia no combate à corrupção. Quando são respeitadas as características essenciais do ser humano, a comunidade tem certeza sobre sua ação como grupo organizado e com poder de decisão, criando-se uma relação de autoconfiança em que as pessoas passam a acreditar mais em si mesmas e nos projetos locais. $\bigcirc$ envolvimento e participação são vistos como instrumentos de auxílio ao desenvolvimento de habilidades e à transformação das pessoas em função de suas próprias necessidades. Para Jara (2001), o maior desafio a enfrentar no desenvolvimento local é garantir a participação dos diferentes grupos na sociedade, favorecendo o controle social sobre o desenvolvimento e elegendo o local enquanto espaço privilegiado da formação de cidadãos.

Para Warschaver (2006), a importância social das TICs decorre do grande potencial de alavancagem, que pode ser empregado para apoiar estratégias mais amplas de inclusão social. $\bigcirc$ autor identifica que um erro comum em projetos de informática social é envolver tecnólogos em vez de líderes comunitários, educadores, administradores e organizadores. $O$ envolvimento dessas pessoas certamente facilita a mobilização comunitária e o compromisso com o projeto, uma vez que elas são referências da comunidade para liderarem as ações, sendo mais simples adquirir a confiança e colaboração dos moradores na execução do projeto. Atendendo a essa concepção, a proposta do Cidadão.NET de incentivar a utilização das ferramentas tecnológicas e da internet para atender a demandas das comunidades procurou induzir a criação de vínculo entre as associações comunitárias e os telecentros, de forma a maximizar a sua utilização como centros de formação e, ao mesmo tempo, realizar os serviços de interesse coletivo. Eram esperados desdobramentos para as comunidades, prevendo impactos na capacidade de aglutinar parceiros interessados no funcionamento do telecentro com a perspectiva de resultados que pudessem levar ao desenvolvimento sócio-econômico local. (IDENE, 2003).

Nessa linha, o Cidadão. NET adotou uma metodologia na qual se considera como pontos fundamentais o protagonismo juvenil e da comunidade, o contexto social, econômico e cultural das localidades onde se encontram os telecentros e o potencial transformador das TICs. A Figura 4 apresenta os atores do projeto.

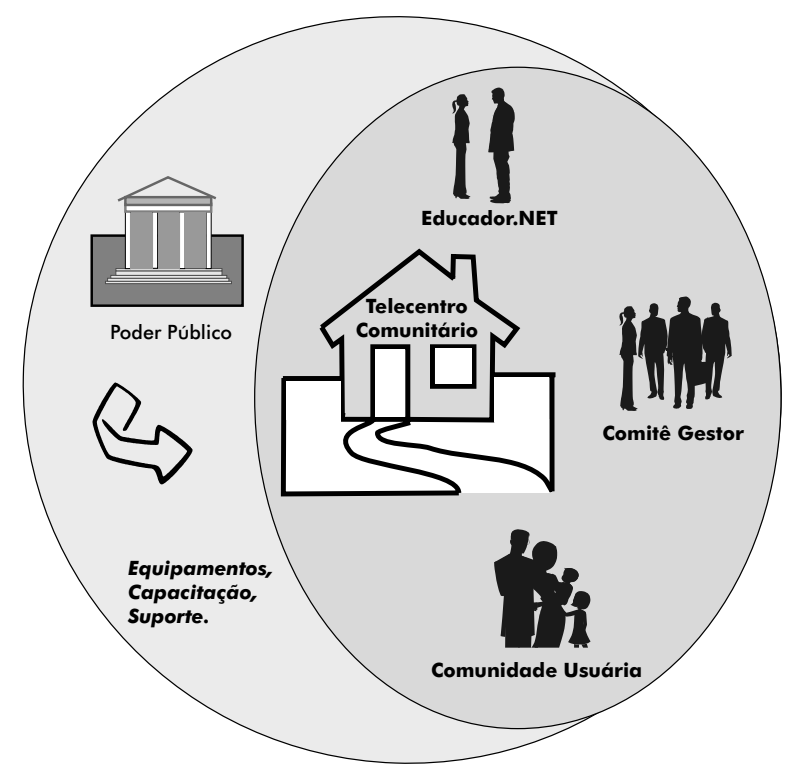

Figura 4. Atores do Cidadão.NET. Fonte: IDENE, 2003. 
A participação da comunidade foi viabilizada por meio do Comitê Gestor (CG) do telecentro comunitário, composto por representantes do poder público municipal e estadual, de tradições religiosas, de movimentos sociais, da associação comunitária conveniada, e de outros segmentos da sociedade interessandos em integrar o projeto. Para atuarem na gestão do telecentro, os membros do CG são convocados periodicamente para encontros de capacitação com o objetivo de trocar experiências entre as unidades de telecentros, discutir problemas e identificar soluções, bem como obter informações e participar de debates sobre gestão participativa, capital social, direito e cidadania. Além disso, procura-se sensibilizar os membros do CG acerca da importância de se utilizar o telecentro como instrumento para o desenvolvimento de ações e projetos de interesse coletivo local.

Um ponto crítico relacionado à efetividade de organização e trabalho do CG é a necessidade do trabalho voluntário por parte de seus membros que, por possuírem outras atividades, não podem ter total dedicação ao projeto. Para Kliksberg (2003), a atividade voluntária, que contraria a fria imagem do ser humano como o homus economicus dos textos de economia, não está movida pela procura de benefícios econômicos nem do poder: é produto de valores éticos e de consciência. Entretanto, numa comunidade reconhecidamente pobre, o trabalho voluntário é mais vulnerável à competição com outras tarefas necessárias à sobrevivência.

Outra figura essencial à concepção do Cidadão.NET é o Educador.NET: jovem estudante do ensino médio ou superior, indicado pelo Comitê Gestor. $O$ perfil do Educador.NET deve incluir interesse e envolvimento com seu contexto social, além de, preferencialmente, noções básicas de informática. É exigida também disponibilidade para atuar no projeto, capacidade de trabalhar em grupo e liderança. A liberdade dada ao CG para selecionar e indicar o Educador.NET procura garantir a co-responsabilidade das pessoas na ação proposta. Ou seja: um morador da comunidade, com seu sotaque e seus costumes, na visão da equipe do projeto, tem maiores chances de sensibilizar e envolver as pessoas nas atividades e ações sociais do telecentro, pela proximidade natural já existente.
Cada telecentro possui três ou quatro Educadores.NET, que são capacitados periodicamente em Informática, Administração de Telecentros, Comunicação, Marketing Pessoal, Empreendedorismo, Ética nas Relações, Direito e Cidadania, e outros temas pontuais. As atividades de capacitação têm o objetivo de preparar o Educador.NET para replicar em sua comunidade aquilo que aprendeu. Dessa forma, durante as capacitações, os Educadores. NET participam de oficinas de criação, com elaboração de cartazes, poemas, paródias, dinâmicas de relacionamento realizadas em conjunto, buscando-se relacionar os vários conteúdos trabalhados com as tecnologias disponíveis no telecentro.

O Universitário.NET é outro ator do projeto, com - papel de acompanhar, avaliar e monitorar as atividades desenvolvidas nos telecentros por meio de contatos diários por e-mail, chat ou telefone e, também, visitas periódicas. Para ser um Universitário.NET, o jovem deve estar cursando graduação em qualquer área do conhecimento e ter interesse e disponibilidade para atuar em projetos sociais. Cabe a eles auxiliar os Educadores. NET nos problemas encontrados nas atividades dos telecentros, além de exercerem a interlocução entre a coordenação do projeto e os telecentros. A capacitação dos universitários enfoca conteúdos similares aos dos demais atores, além de gestão de projetos sociais, inteligências múltiplas, produção de conteúdos para a Web, dentre outros. Os Universitários. NET não tiveram participação na coleta de dados da pesquisa aqui apresentada.

\section{O USO DOS TELECENTROS E SEU IMPACTO SOCIAL}

A seguir são apresentados os dados resultantes da pesquisa empírica no telecentro Comunitário Cidadão.NET do assentamento rural do Projeto Jaiba.

\section{Resultados obtidos com os usuários do telecentro}

Setenta e quatro usuários compareceram ao telecentro no período da pesquisa, e foi-lhes solicitado responder ao questionário. Destes, quarenta e seis (62\%) são do sexo masculino. Igual número tem idade entre 7 e 17 anos, dezoito (24\%) dos respondentes têm idade 
entre 18 e 29 anos e dez (14\%) têm entre 30 e 66 anos de idade. Assim, é perceptível que a maioria dos usuários do Telecentro Comunitário do Projeto Jaíba são crianças e adolescentes. Esse dado reforça a idéia de que o acesso à Internet desperta maior curiosidade e interesse entre a juventude. Por outro lado, é possível entender, também, que tal fato ocorre em função de disporem de mais tempo livre para freqüentar o telecentro.

Mais de $50 \%$ dos usuários do telecentro o freqüentam de duas a três vezes por semana. A figura 5 representa a quantidade de vezes que cada usuário vai ao telecentro por semana e a figura 6, o objetivo da ida. Vinte e oito responderam que estavam ali, naquele momento, para realizar uma pesquisa e digitar trabalho escolar. Segundo eles, na internet conseguem encontrar o tema da pesquisa com informações atualizadas, visto que na escola os livros são velhos e poucos. Vinte e dois usuários responderam que queriam aprender mais sobre como usar o computador e a internet, além de freqüentarem o telecentro para ler e enviar e-mails. Três pessoas procuraram o telecentro apenas para imprimir fotos e textos. Outras vinte e uma buscavam divertir-se por meio do uso de aplicativos de bate-papo virtuais, comunidades virtuais de relacionamentos e jogos, considerando o telecentro como um espaço para encontrar os amigos e divertiremse juntos. Tais respostas destacam as possibilidades de ampliação de relacionamentos distantes, superando limites territoriais, mas, ao mesmo tempo, ressaltam o papel de local de entretenimento e lazer desempenhado

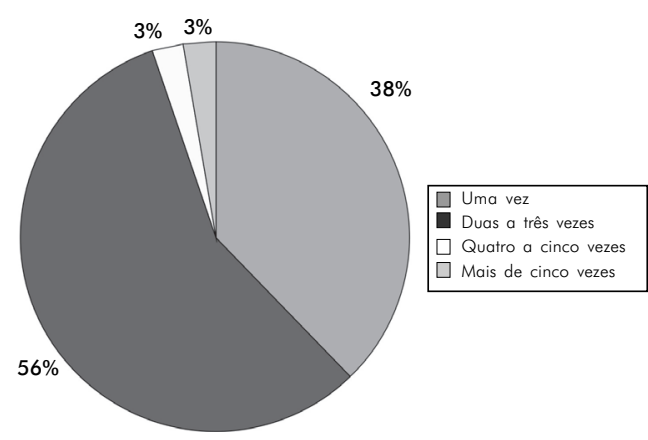

Figura 5. Ida ao telecentro por semana. Fonte: Pesquisa de campo com o uso de questionário, 2006. pelo telecentro numa localidade desprovida de outros espaços culturais.

Uma facilidade bastante mencionada pelos usuários adultos refere-se à rapidez do acesso à informação e comunicação. Justificam que antes precisavam dirigir-se à área urbana mais próxima para buscar informações como, por exemplo, cotações de preços e notícias, e com o acesso à internet, não se faz mais necessário esse deslocamento. A facilidade de comunicação por e-mail também foi bastante citada.

Outro ponto importante apresentado por muitos respondentes em relação à diferença da sua vida antes e depois da instalação do projeto Cidadão.NET é que, segundo eles, se não existisse o telecentro, provavelmente naquele momento da aplicação do questionário estariam em casa, assistindo à TV, visto que na comunidade não existem opções de esporte, lazer e/ou cursos complementares, como os de língua estrangeira.

Cabe destacar que não houve qualquer resposta de interesse no uso do telecentro relacionado à elaboração ou execução de projeto comunitário, publicação de textos ou imagens na Internet que retratem a cultura local ou outra iniciativa que pudesse implicar ação coletiva com foco no desenvolvimento da comunidade. Os interesses manifestados nas respostas ressaltam aspectos individuais e não se pode afirmar que os usuários tenham preocupação ou que percebam o potencial do uso das TICs em prol da comunidade.

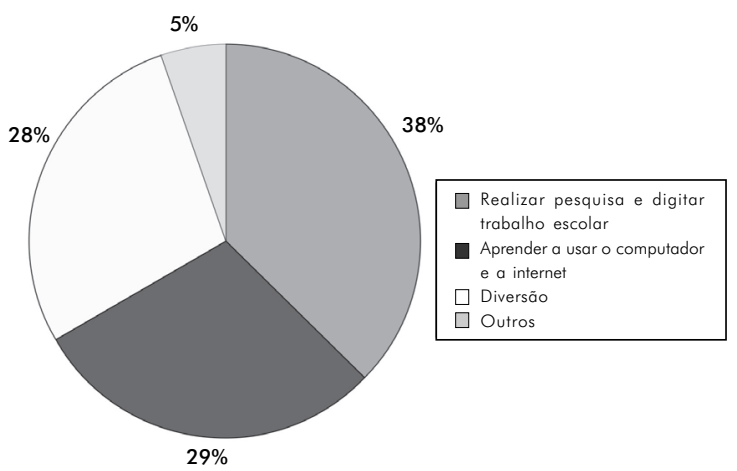

Figura 6. Objetivo da visita ao telecentro. Fonte: Pesquisa de campo com o uso de questionário, 2006. 


\section{RESULTADOS OBTIDOS COM OS EDUCA- DORES.NET}

As respostas obtidas junto aos Educadores.NET não apresentam resultados significativamente diferentes daquelas obtidas com os usuários. São adolescentes e, no caso, todas do sexo feminino. Mostram-se um pouco mais sensibilizadas pelo potencial aberto com o acesso às TICs (talvez decorrente das atividades de capacitação), mas, ainda assim, têm uma visão limitada sobre seu uso.

Indagadas acerca de seu papel no telecentro, declararam ser responsáveis por ministrar cursos, auxiliar e monitorar o uso livre do telecentro e prestar serviços de digitação. Sobre o procedimento de introdução de um novo usuário ao telecentro, as educadoras responderam que, primeiramente, apresentam o projeto Cidadão. NET e as normas do telecentro e, posteriormente, auxiliam o usuário no que for necessário, segundo as demandas trazidas por eles. Pode-se notar que não assumem um papel ativo e propositivo, mas limitam-se ao atendimento puro e simples como suporte ao uso dos computadores e da internet, tarefas para as quais foram capacitadas.

Sobre o treinamento a que foram submetidas, destacaram, além do conteúdo de informática, as atividades de comunicação e cidadania. Além disso, ressaltam a importância de terem conhecido educadores de outros telecentros, pessoas com quem mantêm contato constante por e-mail e programas de mensagens instantâneas. No início do trabalho no telecentro sentiram insegurança e timidez que aos poucos foram vencendo, na medida em que adquiriam maior proficiência e habilidade.

Sobre a comunidade antes e após a implantação do telecentro, as educadoras consideram que as pessoas estão muito mais informadas pela facilidade de acesso a informações por meio das TICs. Mencionaram que as pessoas da comunidade usam a Internet para pesquisa escolar, cotação de preços, segunda via de contas, acesso ao banco, além da comunicação fácil e gratuita com parentes e amigos distantes. Observaram que as pessoas passaram a ter informações que abriram oportunidades, como, por exemplo, os concursos públicos. Antes do telecentro, esse tipo de informação não chegava tão facilmente à comunidade e, por isso, as pessoas não participavam de processos seletivos.
Outro ponto que consideraram importante apresentar diz respeito ao entusiasmo dos estudantes para realização dos trabalhos escolares no telecentro: o aprendizado parece ser maior, pois o próprio estudante faz a sua pesquisa e, para isso, ele precisa ler vários textos, acessar vários sites até encontrar o que deseja. Por essa percepção, pode-se inferir que a internet veio suprir a pobreza da biblioteca escolar local, com fontes de informações mais atualizadas, diversificadas, bem apresentadas e estimulantes.

Como serviços mais utilizados, as educadoras citaram a obtenção de segunda via de contas, o acesso a contas bancárias, o recadastramento de CPF, informações sobre veículos no site do Detran-MG, levantamento de preços dos produtos agrícolas produzidos na comunidade para embasar os produtores rurais na definição do preço de venda.

É interessante destacar que os relatos dos usuários sobre o motivo da ida ao telecentro não coincidem com as afirmativas das Educadoras.NET: concursos, acesso a contas bancárias, pagamento de contas, pesquisa por receitas culinárias, etc. Pode-se perguntar se essa discrepância não decorre do desejo (inconsciente ou não) das educadoras em valorizar a existência e a manutenção do telecentro, mormente se for considerado que, pela função ocupada, elas adquiriram uma certa visibilidade na pequena comunidade, além de receberem remuneração com uma bolsa de trabalho paga com recursos do Projeto Cidadão.NET.

\section{RESULTADOS OBTIDOS COM OS MEMBROS DO COMITÊ GESTOR}

O CG do Telecentro do Projeto Jaíba, é composto por 12 membros, moradores da comunidade, e que desempenham essas funções de forma voluntária. Eles se reúnem mensalmente para discutir problemas da gestão, orientar as Educadoras. NET sobre procedimentos, postura e comportamento, e discutir soluções de sustentabilidade do empreendimento.

$\mathrm{Na}$ opinião dos integrantes do CG, a implantação do telecentro trouxe mudanças para a vida das pessoas da comunidade porque, antes, os residentes no Projeto Jaíba não conheciam tecnologias como computador e internet. Os oito membros do CG 
entrevistados mencionaram que a principal facilidade decorrente da instalação do telecentro foi a obtenção de informações, pelo acesso à internet, sem a necessidade do deslocamento de $45 \mathrm{~km}$ até o centro urbano do município de Jaíba. Isso implicou, também, economia com transporte/ locomoção. Outro benefício apresentado pelos entrevistados é a possibilidade de fazer o recadastramento de CPF e evitar a situação anterior, quando muitas pessoas deixavam de se cadastrar por falta de informação sobre a necessidade e importância de fazê-lo. Pode-se perceber, por esses exemplos, que há um reconhecimento na comunidade de que as pessoas estão mais informadas. $\bigcirc$ uso do telecentro foi vinculado a buscas relacionadas com negócios da comunidade, noticiário, serviços on-line e diversão. Ressaltaram ainda que moradores de outras glebas do Projeto Jaíba, distantes até $15 \mathrm{~km}$ do local do telecentro, vencem a distância para usar os recursos ali disponíveis. Este uso só não é maior pela dificuldade de locomoção, dada a ausência de transporte público eficiente.

Quando questionados sobre a auto-sustentação para o telecentro, todos os entrevistados responderam que é um ponto de difícil solução. Segundo eles, no Projeto Jaíba não há parceiros potenciais para o telecentro; os pequenos comerciantes não têm interesse em apoiar a iniciativa. A forma ideal, na opinião de todos os entrevistados, seria pedir colaboração dos usuários que pudessem e quisessem pagar uma pequena taxa pelo uso do local, mas essa forma de arrecadação não é permitida, por determinação do projeto Cidadão.NET. Uma alternativa seria a constituição do "Amigo do telecentro": pessoa (física ou jurídica) que quisesse ajudar o telecentro a manter-se e a permanecer na comunidade. Essa poessibilidade, entretanto, ainda não foi posta em prática.

\section{CONSIDERAÇÕES FINAIS}

Este trabalho apresentov e analisou o projeto Cidadão.NET, que tem como meta promover a inclusão digital com vistas ao desenvolvimento humano local. Como muitos outros projetos existentes no Brasil, o Cidadão.NET utiliza o telecentro como espaço preparado para facilitar o acesso da população aos computadores e à internet. O objetivo da pesquisa foi investigar as conseqüências das ações de inclusão digital em uma comunidade rural, buscando identificar tendências locais de desenvolvimento, apoiando-se principalmente nas concepções de Sen (2000) e de Kliksberg (2003), mencionadas anteriormente.

O Telecentro Comunitário do Projeto Jaíba oferece para a comunidade treinamento em conteúdos de informática e cidadania, uso livre do computador e da Internet, serviço de produção de conteúdo comunitário, como, por exemplo, folhetos com cânticos religiosos para os ofícios das igrejas, cartazes de divulgação de eventos etc., e serviços privados ampliados, como atividades bancárias, emissão de segunda via de contas, pagamentos de taxas e multas etc...

As pessoas da comunidade começam a associar o telecentro a um espaço onde é possível identificar e atender seus interesses pessoais, como uso de serviços do Detran, da Receita Federal, pesquisas escolares, comunicação com pessoas distantes, participação em rede de relacionamentos e outras facilidades. Vale destacar, no entanto, que ainda não ocorreu a apropriação das tecnologias para benefício coletivo, com elaboração de projetos e ações que tragam melhorias para a comunidade. Essa constatação vem reforçar o questionamento a algumas visões utópicas que esperam o advento da modernização e do progresso sócio-cultural pela simples disseminação do acesso às TICs.

Os resultados obtidos permitem supor que a comunidade mais diretamente atendida pelo telecentro, os moradores do Núcleo Habitacional 02 da gleba $F$ do Projeto Jaíba, ainda não se apropriou das TICs, ressignificando-as em seu cotidiano para benefício conjunto da comunidade. As pessoas percebem que as tecnologias diminuem as distâncias, trazem notícias do resto do mundo e facilitam algumas tarefas; entretanto o relato do uso primordial retrata a primazia dos interesses particulares e funcionais. Pode-se afirmar que a comunidade carece de organização local em torno de projetos coletivos que contribuam para a ressignificação de conteúdos apreendidos na própria realidade, no sentido de ampliar o protagonismo e a reconfiguração do cotidiano das pessoas. Na mesma direção apontam as respostas acerca da ausência de iniciativas para o sustento e manutenção do telecentro.

Merece destaque a ênfase no uso, pelos jovens, dos recursos de comunicação e sociabilidade, como participação em comunidades virtuais e sites de 
relacionamentos. Essa constatação dá margem a duas interpretações antagônicas. Por um lado, pode significar ampliação do campo de interesses o que, a médio e longo prazo, poderia trazer profundas alterações para a vida dos moradores da área estudada. Em outra perspectiva, menos positiva, pode ser entendido como uma fuga da realidade monótona e desinteressante do local. Uma visão otimista permitiria contudo, conciliar ambos os aspectos: uma motivação conduziria à outra. O telecentro do Cidadão.NET ainda é uma iniciativa muito recente para permitir qualquer conclusão definitiva. De toda forma é inegável que o telecentro introduziu alterações nas práticas sociais e culturais da comunidade.

Concluída a pesquisa, é possível afirmar que as facilidades trazidas pela rapidez de acesso à informação, assim como a organização de grupos da comunidade no Projeto Jaíba em prol da gestão e uso do telecentro, têm apontado novos caminhos às pessoas e propiciado a emergência de lideranças jovens. É importante, entretanto, ressaltar que os resultados confirmam as observações de Loureiro (2002) de que a disseminação

\section{REFERÊNCIAS}

ALBUQUERQUE. H.H.F.S. Inclusão digital para a redução de desigualdades sociais: a apropriação e o uso das tecnologias da informação para a atuação cidadã. 2005. 129f. Dissertação (mestrado em Ciência da Informação) - Escola de Ciência da Informação, Universidade Federal de Minas Gerais, 2005.

BABE, R.E. Communication and the transformation of economics: essays in information, public policy and political economy. Boulder, Westview Press, 1995.

CÂMARA, M.A. Telecentros como instrumento de inclusão digital: perspectiva comparada em Minas Gerais. 2005. 134f. Dissertação (mestrado em Ciênci da Informação) - Escola de Ciência da Informação, Universidade Federal de Minas Gerais, 2005.

CASTELLS, M. A sociedade em rede. São Paulo: Paz e Terra, 1999.

DARELLI, L.E. Telecentro como instrumento de inclusão digital para o E-gov brasileiro. 2003. 123f. Dissertação (mestrado em engenharia de produção) - Departamento de Engenharia de Produção e Sistemas, Universidade Federal de Santa Catarina, 2003.

FGV - Fundação Getúlio Vargas. Mapa da exclusão digital. Rio de Janeiro: FGV/ IBRE, CPS, 2003. da informação "não se configura per si instrumento de transformações. Ela somente se tornará fator de transformações efetivas quando vivenciada pelos sujeitos informacionais de maneira crítica".

Portanto, pode ser constatado que o objetivo maior do Cidadão.NET - o desenvolvimento humano local - ainda não foi alcançado. Ainda há, contudo, muito a ser aprendido sobre processos de inclusão digital, formação de redes sociais, afluência de idéias e informações por meio de associações humanas no mundo virtual. O que já parece claro é que estamos diante de um fenômeno que nos força a pensar a importância da participação comunitária em políticas públicas de inclusão digital, bem como acerca da eventual ampliação dos horizontes, a partir do acesso às TICs, daquelas pessoas consideradas "excluídas do mundo digital".

Existe um longo caminho a percorrer para o melhor entendimento dessa nova configuração tecnologia/sociedade, e a composição dos saberes se fará por meio de outros estudos que complementem o recorte aqui apresentado.
GESAC. Manual do GESAC - Governo Eletrônico: Serviço de Atendimento ao Cidadão. Ministério das Comunicações. Disponível em: <http://www.idbrasil.gov.br>. Acesso em: ago. 2006.

GUESSER, A.H. A construção de um paradigma colaborativo: a experiência do movimento software livre e a luta por maior inclusão na sociedade da informação. Revista Inclusão Social, v.2, n. 1, p.47-59, 2006.

IBICT. Mapa de inclusão digital, 2007. Disponível em: <http:// www.inclusao.ibict.br>. Acesso em: dez. 2007.

IDENE. Projeto de inclusão digital Cidadão.NET. 2003. Texto de referência do projeto. 2003.

JARA, C. As Dimensões intangíveis do desenvolvimento sustentável. Brasília, DF: IICA, 2001.

KLIKSBERG, B. Por uma economia com face mais humana. Brasília: UNESCO, 2003.

LABSL - Laboratório Software Livre. Projeto Cidadão.NET: diagnóstico da situação atual dos telecentros e diretrizes para a qualificação do seu uso. Belo Horizonte: UFMG, 2006.

LEITÃO, U. et al. Terminais inteligentes: alternativa estratégica para otimização de recursos computacionais. [S,I.]: DoctumTec, 2004. 
LÉVY, P. Cibercultura. Tradução de Carlos Irineu da Costa. São Paulo: Editora 34, 1999.

LIBERTASBR. Projeto LibertasBR. 2003. Disponível em: <http:// www.libertasbr.org.br>. Acesso em: nov. 2006.

LIMA, A.M.M.A. Inclusão digital e protagonismo juvenil: um estudo em dois centros de tecnologia comunitária. 2005. 156f. Dissertação (mestrado em educação) - Pontifícia Universidade Católica de São Paulo, 2005.

LOUREIRO, J.M.M. Socialização da informação: nadando contra a corrente. Informação e Sociedade: Estudos, v. 12, n.2, p.81 93, 2002.

MATTOS, F.A.M. Inclusão digital e desenvolvimento econômico na construção da sociedade da informação no Brasil. Revista Datagrama Zero, v.7, n.3, 2006. Disponível em: <http:// www.datagramazero.org.br/jun06/F__art.htm > . Acesso em: 20 jan. 2007.

IBGE - Instituto Brasileiro de Geografia e Estatística. Pesquisa Nacional por Amostra de Domicílios.[S.I.] IBGE, 2005.

PROENZA, F. Telecentros: mitos y oportunidades sobre la sustentabilidad. In: ARAYA D.R.; PORRUA V.M. (org). América
Latina Puntogob: casos y tendencias en gobierno electronico. Santiago, Chile: FLACSO, 2004.

SCHWARTZMAN, S.; REIS, E. Pobreza e exclusão social: aspectos sócio políticos. Versão preliminar. World Bank. 2002. Disponível em: <www.schwartzman.org.br/simon/pdf/exclusion.pdf > . Acesso em: abr. 2008.

SEN, A. Desenvolvimento como liberdade. São Paulo: Companhia das Letras, 2000.

SILVEIRA, S.A. Exclusão digital: a miséria na era da informação. São Paulo: Fundação Perseu Abramo, 2001.

SILVEIRA, S.A. Soffware livre e inclusão digital. São Paulo: Conrad, 2003.

TRIVIÑOS, A.N.S. Introdução à pesquisa em ciências sociais: a pesquisa qualitativa em educação. São Paulo: Atlas, 1987.

WARSCHAUER, M. Tecnologia e inclusão social: a exclusão digital em debate. Tradução Carlos Zlak. São Paulo: Editora SENAC São Paulo, 2006. 